\title{
Descompasso na saúde pública: o acesso à justiça e a judicialização versos o direito à saúde na Constituição de 1988
}

\author{
Mismatch in public health: access to justice and judicialization versus the right to health in \\ the Constitution of 1988
}

\author{
Beatriz Casagrande Fortunato \\ Universidade Estadual do Norte do Paraná - UENP \\ Mestre em Ciência Jurídica \\ Marília, São Paulo, Brasil \\ bia_fortunato@hotmail.com \\ Marcos César Botelho \\ Universidade Estadual do Norte do Paraná - UENP \\ Doutor em Direito Constitucional \\ Tupã, São Paulo, Brasil \\ mc_botelho@yahoo.com.br
}

Resumo: A realidade brasileira nacional dos últimos anos é de inúmeros processos judiciais solicitando a prestação de serviços com fundamento no direito à saúde, seja pela ineficiência e/ou ineficácia das políticas públicas existentes, ou então sua inexistência. Essa situação, conhecida como judicialização da saúde, pode conduzir os juízes a interpretações exacerbadas aplicando e determinando a efetivação de um direito a saúde de forma ilimitada. Consequentemente, os processos, carregam desigualdades e desproporcionalidades, vez que beneficiam tão somente seus demandantes quando procedentes. Desse modo, diante desse contexto, o presente trabalho, a luz do método dedutivo, pretende demonstrar que os problemas da judicialização da saúde simbolizam uma forma desigual de acessar prestações e serviços de saúde, e até mesmo desproporcional, considerando a exequibilidade das decisões judiciacias. Destarte, conclui-se pela necessidade de uma justiça por equidade, a partir do apoio técnico especializado ao magistrado, como a platarforma e-NATJus.

Palavras-chave: direito à saúde; judicialização; equidade; apoio técnico ao judiciário.

Abstract:The brazilian reality in the last few years is a lot of lawsuits requesting the provision of services based on the right to health, either due to the inefficiency and or ineffectiveness of existing public policies, or their inexistence. This situation, known as the judicialization of health, can lead judges to exagerated interpretations by applying and determining the realization of the right to health in an unlimited way. Consequently, the lawsuits carry inequalities and disproportionalities, because they only benefit their plaintiffs when it is proceeding. Therefore, in this context, this work, based in the deductive method, intends to demonstrate that the problems of the judicialization of health symbolizes an unequal way of accessing health services, and even disproportionate, considering the feasibility of judicial decisions. Thus, in conclusion,there is a need for fairness based on specialized technical support to the judge, such as the e-NATJus platform.

Keywords: right to health; judicialization; equity; technical support to judiciary. 


\section{Introdução}

A Constituição da República Federativa do Brasil de 1988 é importante e marcante por ter positivado inúmeros direitos e garantias pela primeira vez na história do país, até porque ela traz uma nova fase de valorização de direitos fundamentais, inerentes ao ser humano, bem comoa importância da dignidade humana, embora não seja composta apenas deles, também traçando diretrizes organizacionais ao Estado, as funções estatais, bem como deveres as pessoas, aos governantes, aos magistrados e outros.

Por sua vez, os direitos previstos constitucionalmente são tidos como cláusulas pétreas, ou seja, não podem ser suprimidos ou alterados. Esses direitos podem ser individuais ou coletivos, dentre os quais, existem os que servem ao ser humano considerado em si mesmo e aqueles assegurados a todos como um grupo, determinável ou indeterminável.

Em especial, o direito à saúde está previsto na Constituição Federal, e é classificado como um direito social, cujo principal intuito é sua garantia ao grupo, de forma igualitária. Para tanto, o Sistema Único de Saúde é a instituição nacional responsável pela promoção, recuperação e proteção da saúde. De outro lado, em razão dos problemas com políticas públicas, o Poder Judiciário acaba sendo a via escolhida para as pessoas pleitearem prestações de saúde a serem fornecidas pelo poder público.

Logo, diante da positivação irrestrita entre a possibilidade de acesso à justiça, bem assim a maneira como o direito à saúde foi positivado, e não vem sendo concretizado, o resultado são inúmeros processos judiciais, devido a políticas públicas mal executadas e/ou inexistentes,ocasionando, consequentemente, problemas orçamentários, institucionais, dentreoutros, tendo em vista as ordens advindas das decisões judiciais, em sua maioria,voltadas ao fornecimento ou custeio dos medicamentos, tratamentos, cirurgias e demais pleitos.

Posto isto, o presente trabalho busca questionar a atuação judicial que muitas vezes garante a procedência dos pleitos de forma pouco criteriosa, como se o direito à saúde fosse absoluto e irrestrito, demonstrando, na verdade,que precisa de aparatos, os quais possibilitem decisões mais justas e equânimes, isto é, mediante um apoio técnico especializado e simples, haja vista a celeridade que os casos processuais de saúde exigem. Para tanto, utilizou-se o método dedutivo,as técnicas de coleta de dados bibliográficos, documentais e via internet. 


\section{0 direito constitucional à saúde}

A saúde foi erigida como direito pela Constituição da República de 1988 no Brasil, sendo tratada como um direito social e de todos, cujo dever do Estado é garanti-la a partir de políticas sociais e econômicas com o objetivo de reduzir o risco de doenças e outros agravos, tal qual proporcionar o acesso universal e igualitário, as ações e serviços de saúde em prol de sua promoção, recuperação e proteção (BRASIL, online).

Nesta toada, verifica-se que a saúde depende de características individuais, físicas e psicológicas, bem como do ambiente social e econômico, inclusive o que está próximo das pessoas e o que condiciona a sua vida. Assim, "a saúde deverá inevitavelmente implicar aspectos individuais, sociais e de desenvolvimento" (DALLARI; NUNES JÚNIOR, 2010, p. $11)$.

Então, quando se trata de saúde, esta não significa apenas as condições e tratamentos de patologias desenvolvidas pelo ser humano, mas sim, também,a relação ser, meio ambiente, Estado e outros seres humanos, visto que o meio influencia as condições e a maneira de viver do ser humano, e, via reflexa, a sua saúde.

Dessa forma, a maneira como o direito à saúde foi positivado constitucionalmente implica no Estado brasileiro se organizar para atuar na relação entre os seres humanos e todo o ambiente que os cerca, no sentido de protegê-lo, recuperá-lo e promover a sua saúde, isto é, condições que melhorem a sua vida em termos qualitativos.

Isso porque, a saúde é definida pela Constituição da Organização Mundial da Saúde de 1946, como "é um estado de completo bem-estar físico, mental e social, e não consiste apenas na ausência de doença ou de enfermidade" (OMS/WHO, online).

Marco Segre e Flávio Carvalho Ferraz (1997, p. 539-540) criticam a definição de saúde da OMS, uma vez que são utilizadas as palavras perfeição/completoe bem-estar, cuja conceituação é subjetiva, sendo que corresponde ao estilo de vida de cada indivíduo. Eles argumentam em favor de um conceito objetivo, a partir do qual ao invés de mensurar e qualificar o perfeito ou o completo bem-estar segundo avaliações externas e estatísticas, além deconsiderarem que o destaque ao físico, mental e social é algo superado, pois com a vivência psicanalítica, nota-se a inexistência entre a mente e soma, "sendo o social também inter-agente, de forma nem sempre muito clara, com os dois aspectos mencionados".

Eis que, "sob o aspecto jurídico, devemos entender saúde como o bem fundamental que por meio da integração dinâmica de aspectos individuais, coletivos e de desenvolvimento visa 
assegurar ao indivíduo o estado de completo bem-estar físico, psíquico e social” segundo Sueli Dallari e Vidal Serrano Nunes Júnior (2010, p. 13).

Logo, a garantia de uma melhor qualidade de vida do ser humano em sociedade e da sociedade como um todo implica em ações de proteção, promoção e recuperação de saúde, ou seja, condições que lhe proporcionem o bem-estar físico, psíquico individual e social. Garantir completamente tal bem-estar parece não se coadunar com todos os objetivos e funções do Estado Brasileiro, de modo que melhor seria pensar na garantia efetiva de bem-estar aos cidadãos, sendo cada vez mais admitida e buscada sua potencialização, o que se dá através do desenvolvimento de técnicas de tratamento de enfermidades, vacinas, e não só por meios laboratoriais artificiais como de técnicas naturais.

Posto isso, o direito à saúde é classificado constitucionalmente como social, visto que:

no âmbito do Estado Social e Assistencialista, os direitos sociais como nova categoria de direitos fundamentais, carregam em si a incumbência de possibilitar a concretização da proclamada igualdade liberal que se mostrou meramente formal, através da garantia efetiva de direitos que assegurem a proteção da dignidade do ser humano, que só poderiam ser realizados por meio de condutas prestacionais do Estado (SERRANO, 2012, p. 46).

Ademais, Serrano (2012, p. 49) também assevera que os direitos sociais, por serem direitos fundamentais, não podem ser renunciados, porque funcionam como garantia de uma vida humana digna, sendo destinados a todo e qualquer ser humano sem restrição.

Com efeito, após a garantia da liberdade aos homens, foi necessário assegurar a igualdade material e fática entre eles mediante algumas prestações, o que, de início, não aconteceu, porém esse é o propósito dos direitos sociais.

A seu turno, para Vidal Serrano Júnior (2009, p.70), os direitos sociais são:

o subsistema dos direitos fundamentais que, reconhecendo a existência de um segmento social economicamente vulnerável, busca, quer por meio da atribuição de direitos prestacionais, quer pela normatização e regulação das relações econômicas ou ainda pela criação de instrumentos assecuratórios de tais direitos, atribuir a todos os benefícios da vida em sociedade.

Enquanto direito social, o direito à saúde ampara não só os economicamente vulneráveis, mas sim todas as pessoas,consistindo em um direito prestacional cujo escopo é proporcionar a todos os benefícios da vida em sociedade. Dessa forma, assegurar o direito à saúde demanda uma boa gestão econômica e política, justamente pelo fato de se tratar de um direito que precisa ser prestado no tocante à proteção, recuperação e prevenção da saúde do indivíduo. 
Cumpre observar que: "A universalização da saúde foi acompanhada de sua institucionalização normativa, o que possibilitou a cristalização de princípios, normas e diretrizes que seriam desenvolvidos nos anos seguintes, cuja expressão mais significativa foi a criação do Sistema Único de Saúde (SUS)” (MARQUES et al, 2019, p. 218).

Nesse sentido, a universalidade que o direito à saúde carrega envolve:

\begin{abstract}
A universalidade da cobertura, também conhecida como universalidade objetiva, é aquela que visa a uma total cobertura das ações e dos serviços de saúde. Ela é relacionada, desta forma, com a proteção de todos os riscos sociais relativos à saúde da população.

Por sua vez, a universalidade do atendimento, ou universalidade subjetiva, tem relação direta com os destinatários do direito à saúde, ou seja, quais pessoas serão atendidas quando tiverem qualquer contingência sanitária. A universalidade do atendimento visa a estabelecer um sistema de saúde igualitário, sem qualquer discriminação quanto aos sujeitos detentores do direito à saúde (CUNHA, 2019, p. 172).
\end{abstract}

Em vista disso, a cobertura de saúde deve ser para todos de forma ampla e irrestrita no que tange a ações e serviços, inclusive eventuais riscos, bem como a sua destinação, uma vez que toda pessoa é detentora do direito à saúde, porém, o seu o atendimento dar-se-á nos casos de prevenção, proteção e recuperação, como nas vacinações, medicamentos, cirurgias, e os variados tipos de tratamento.

Cabe elucidar que a Constituição garante a todos os seres humanos as mesmas condições de acesso ao sistema público de saúde, o que não culmina em qualquer pessoa, em qualquer da situação, ter um direito subjetivo definitivo a qualquer prestação oferecida pelo Estado ou que se relacione à proteção de sua saúde (SARLET, 2018, p. 339). Isto é, sob o aspecto coletivo, o direito à saúde deve ser abordado com a devida relevância a ponto das pessoas terem consciência de que seu direito (individual) à saúde não é ilimitado.

Para tanto, é preciso “determinar prioridades na alocação de recursos públicos em saúde depende de estudos acerca de quais seriam as doenças prioritárias, o que significa decidir que os serviços sanitários escolhidos para seu tratamento e prevenção serão considerados prioritários em face de outros" (BARCELLOS et al., 2017, p. 460).

Por isso a importância também da seletividade pelo gestor público a fim de escolher as contingências mais necessárias de serem combatidas e tratadas no momento, considerando seus riscos, e, a distributividade, no sentido de, haja vista o direito não poder ser concretizado para todos, que ele seja restrito a determinada parcela da população, entendida como necessitada pelo gestor público, na forma de prestação de serviços (CUNHA, 2019, p. 173-174).

Portanto, o direito à saúde preza pelo acesso universal às prestações de saúdede e para todas as pessoas, em contrapartida, enquanto direito subjetivo exige razoabilidade na análise da 
situação fática da contingência como urgência, emergência ou situação eletiva, exigindo, então, planejamento na sua gestão por parte dos gestores públicos e governantes, visto que as necessidades humanas sempre serão ilimitadas, todavia, o orçamento público é limitado.

No Brasil, as medidas em prol da promoção, proteção e recuperação da saúde, isto é, as ações governamentais tomadas para assegurar o direito à saúde são de atribuição constitucional do Sistema Único de Saúde, pautado pelo princípio da universalidade, consistindo em umainstituição pública e nacional que oferecerá assistência à saúde e atenderá a todos os seres humanos. Suas diretrizes são: a descentralização, a integridade no atendimento e a participação da comunidade. (FIGUEIREDO, 2007, p. 97).

Apesar do SUS ser o responsável pela execução das políticas públicas de saúde, a demanda se mostra muito mais elevada do que a possibilidade dos cofres públicos, em especial devido à quantidade de solicitações por medicamentos, cirurgias e tratamentos, como também em termos de valores, cirurgias, medicamentos e tratamentos caros, estando alguns cobertos ou não pelo Sistema, e outros não disponíveis de pronto.

Dessarte,

Ainda que a positivação dos direitos humanos assuma mais a forma de uma declaração
de direitos fundamentais que de um programa político constitucional - em ambos os
casos, as possibilidades de vincular tanto a entidade jurídica como a entidade do
Estado, desde o começo, a princípios da justiça, não estão esgotadas. Para que a
obrigação da justiça chegue a seu pleno desempenho, existe um instrumental de etapas
que começa com a garantia dos direitos humanos e continua na veiculação da
legislação com a constituição, bem como o exame desta veiculação pela suprema corte
como um tribunal constitucional. E ainda, o governo e a administração devem estar
submetidos à constituição e às leis conformes com a constituição, e esta submissão
necessita novamente de exame, por exemplo, na forma de tribunais administrativos
(HOFFE, 2006, p. 421-422).

Hoffe considerava que o homem vivia num estado primário de natureza ampla liberdade, e que o exercício da liberdade irrestrita de cada um dos homens gerava conflitos, de forma que a vida social surgiu a partir de um acordo de restrição da ampla liberdade entre os homens. Sendo assim, também se fez necessário a instituição de um poder maior para regulamentar e organizar a vida social, o qual é representado pelo Estado, cuja melhor acepção foi de um Estado Constitucional Democrático, considerando que a Constituição detém a função de limitar o poder do governante e garantir os princípios da justiça, na modernidade conhecidos como direitos humanos, dado que o poder do Estado pode se tornar arbitrário se não contiver limitações e finalidades, tal qual a necessidade de outros poderes atuando em prol da garantia de direitos (a justiça para Hoffe) caso o poder governamental não os assegure. 
Por conseguinte, Hoffe adverte que os direitos humanos devem estar positivados numa constituição, da qual devem emanar as atividades e ações governamentais, e ainda, que haja um tribunal constitucional para garantia desses direitos.

Assim, a saúde foi positivada como um direito humano fundamental (e social) pela Constituição Brasileira de 1988, tal qual o Sistema Único de Saúde foi criado para a execução das ações em favor da saúde como um direito, de maneira ampla e irrestrita. No entanto, o dilema nacional tem sido delimitar, e até que ponto, a sua garantia pelo Estado através do Poder Judiciário pode culminar em exceder os limites sociais e orçamentários.

\section{A judicialização da saúde e o ativismo judicial no Brasil}

A ineficácia e/ou ineficiência das ações governamentais pelo SUS no atendimento do direito à saúde de inúmeros brasileiros têm os conduzido ao Poder Judiciário como aquele que irá lhes proporcionar o que almejam, isso porque, para o senso comum, este é poder que lhes transmite mais credibilidade e confiança nos últimos anos.

Com efeito, são várias as ações judiciais demandando medicamentos de alto ou baixo custo, fornecidos ou não pelo SUS, cirurgias, e tratamentos dos mais variados, abrangidos ou não pelo Sistema Único de Saúde.Tal situação ficou conhecida como judicialização da saúde.

Na acepção de Vanice Lírio do Valle (2011, p. 199), esse movimento de demandas individuais buscando remédios, internações, exames, intervenções cirúrgicas e outras prestações relacionadas à preservação da saúde decorre da desfuncionalidade no início da implementação do SUS, aliada a deficiência na oferta dos serviços públicos de saúde cujo objetivo era que eles fossem prestados de forma universal.

A judicialização não se refere apenas ao aumento importante, generalizado, e direto que os tribunais vêm desempenhando em fazer política. $\mathrm{O}$ fato dos tribunais estarem frequentemente intervindo no processo de elaboração de políticas significa que outros atores políticos como grupos que defendem as ações políticas, têm motivos e possibilidades de desencadear uma reação judicial em cadeia. Então, as propostas devem enquadradas de forma a garantir que a legislação não será derrubada, nem interpretada de forma indesejável. A fim de atingir esse resultado, parte do debate da nova legislação deve ter como objetivo antecipar a reação das instituições legais defende John Ferejohn (2002, p. 41-42).

Logo, a judicialização se relaciona com a intervenção judicial na política, dado que as decisões sobre saúde e outros direitos sociais, se positivas para os autores vão fazer com que o Poder Público realize a prestação solicitada no prazo aventado pelo juiz, e/ou segundo os 
valores por ele estabelecidos. Via reflexa, o poder público deixará de cumprir sua agenda econômica ou de medidas de saúde para dar cumprimento à decisão judicial, porque ela é coercitiva, e se não cumprida, pode ensejar multa.

Nesse sentido, somem-se aqueles que consideram a judicialização como uma forma de utilizar os tribunais para satisfazer interesses:

\begin{abstract}
A judicialização da política é um processo que se alimenta dos interesses econômicos e sociais centrais, que por sua vez estruturam o sistema político. De fato, o desenvolvimento e a expansão dos direitos em geral, até mesmo dos direitos políticos, foram mais propriamente obra de pressões e lutas das organizações sociais, sejam elas movimentos sociais ou grupos de interesse, do que obra de devoção de atores altruístas. Portanto, os grupos de interesse passam a considerar e/ou utilizar a possibilidade de veto dos tribunais na realização de seus objetivos (DE CARVALHO, 2004, p. 118).
\end{abstract}

As pessoas carentes, mais necessitadas, e menos informadas, apesar de deterem o direito, não têm a facilidade ao acesso à justiça que as pessoas mais informadas e, consequentemente, que possuem uma condição de vida melhor detém. Assim, o governo, em uma tentativa de balancear as demandas, emprega mais recursos para a resolução de processos judiciais no custeio de tratamentos deferidos a título de tutela antecipada ou em sentenças, do que investindo em saúde e saneamento básico - considerando-se os gatos a curto prazo. Desse modo, ocorre uma inversão de prioridades e necessidades haja vista as "despesas" com judicialização.

Insta salientar que a falta de saneamento básico fere não só os direitos mais fundamentais do ser humano, como lhe sujeita a doenças, a um ambiente insalubre, que se alastra sem que existam os devidos cuidados e também sem amparo.

Manuel Gonçalves Ferreira Filho (1996, p. 189) considera como judicialização a atribuição ao Judiciário de decisões que originalmente pertenceriam aos Poderes Legislativos ou Executivo por se tratarem de decisões políticas, posto que afetam o destino da comunidade ou consistem na orientação de determinados objetivos do governo a partir de uma visão do bem comum.

Destarte, a judicialização é o efeito da delegação indireta pela inação ou omissão dos poderes Executivo e Legislativo na tomada de decisões ou da escolha e realização políticas públicas que interferem na vida do povo em favor de seu bem.

Dessa forma, não tem como o judiciário amparar completamente a pessoa que busca com a sua demanda uma prestação de saúde, concedendo a ela o tratamento mais caro e mais custoso, inclusive em termos de uma eficácia mais dificultosa, porque no Brasil são inúmeras as carências, inclusive e especialmente no tocante à saúde, o que exige a realização das políticas 
públicas existentes para determinadas situações, bem como seu aprimoramento e aperfeiçoamento.

Sendo assim,

Talvez o grande problema esteja na distinção entre judicialização e ativismo. A primeira acontece porque decorre de (in)competências de poderes e instituições, abrindo caminho-espaço para demandas das mais variadas junto ao Judiciário; a segunda é, digamos assim, behaviorista, dependendo da visão individual de cada julgador. A judicialização pode ser inexorável, o ativismo não. $\mathrm{O}$ ativismo não faz bem à democracia (STRECK, 2015, p. 8).

A judicialização da saúde é um fenômeno decorrente do problema de prestação dos serviços de saúde por parte do poder público, uma vez que há uma ineficiência ou ineficácia neste serviço, de modo que ele não é prestado ou ofertado tal como o esperado/desejado. Por sua vez, o ativismo judicial ocorre quando o magistrado implanta sua visão e posição pessoal no processo para a resolução da lide.

Nessa esteira, verifica-se que a autonomia dos magistrados não pode se tornar excessiva a ponto deles exteriorizarem suas próprias vontades no processo, igualmente, não pode haver um excesso de adesão aos princípios constitucionais, porque eles também levariam a sua aplicação ao entendimento subjetivo e aberto do julgador, viabilizando um exercício de interpretação e aplicação da autonomia do juiz. De certo, a autonomia judicial deve ser limitada as regras, aos princípios e aos conteúdos normativos para evitar arbitrariedades (MACHADO, 2011, p. 113).

Logo, o ativismo judicial pode ser entendido como um exercício de arbitrariedade do magistrado, extrapolando sua autonomia interpretativa de atuação, o que gera prejuízos quanto à suapostura e a aplicação do direito, pois o juiz enquanto conhecedor do direito sabe os limites que pode atingir em suas decisões e interpretações, e, caso existam excessos, não só a exequibilidade da decisão estará prejudicada, bem comoo direito como instituto e a função do magistradonos sistema jurídico.

O objetivo do processo é a melhor e mais adequada solução em tempo razoável e que possa ser executada sem onerar excessivamente a parte que a cumprirá, além disso, o processo é um instrumento de pacificação social. O juiz é o seu condutor, após ser provocado, devendo zelar pelo cumprimento de suas funções na condução processual, visto que existe todo um aparato legislativo a ampará-lo em termos materiais e procedimentais. Por isso, extrapolar esse campo, atribuindo-se uma autonomia que vá além de seu livre convencimento da causa, prejudicando a demanda e sua resolução que não poderá ser eficaz e efetiva, dá margem para a disseminação do excesso de autonomia deliberado em momentos não declarados e permitidos 
legalmente, e, torna instável a forma de decidir no ordenamento jurídico pátrio.Como consequência, com o tempo, a legislação também padecerá de confiabilidade por parte da população e se tornará instável.

Barroso (2012, p. 10), a seu turno, considera a judicialização como efeito do desenho institucional brasileiro, enquanto que o ativismo consiste na forma proativa de interpretar a Constituição, a ponto de expandir seu alcance e seu sentido. No Brasil, o ativismo se alocou devido à retração do Poder Legislativo e de um descolamento entre a classe política e civil, cujo resultado foi o impedimento de atender efetivamente certas demandas. A auto-contenção judicial, por sua vez, é o oposto do ativismo, dado que nela a participação e atuação dos poderes políticos é maior, tendo em vista suas omissões, falhas, e ações anteriores.

Segundo Gisele Cittadino (2004, p. 106):

O crescente processo de "juridificação" das diversas esferas da vida social só é
compatível com uma filosofia constitucional comprometida com o ideal da igualdade-
dignidade humanas e com a participação político-jurídica da comunidade. Em
segundo lugar, ainda que o processo de judicialização da política possa evocar um
vínculo entre "força do direito" e "fim da política" - ou seja, a idéia de que as
democracias marcadas pelas paixões políticas estariam sendo substituídas por
democracias mais jurídicas, mais reguladoras -, é preciso não esquecer que a crescente
busca, no âmbito dos tribunais, pela concretização de direitos individuais e/ou
coletivos também representa uma forma de participação no processo político.
Finalmente, é importante considerar que se a independência institucional do Poder
Judiciário tem como contrapartida a sua passividade-o juiz só se manifesta mediante
provocação -, os tribunais estão mais abertos ao cidadão que as demais instituições
políticas e não podem deixar de dar alguma resposta às demandas que lhe são
apresentadas.

Isso posto, verifica-se a Constituição Cidadã brasileiraestimulou esse fenômeno de muitos processos judiciais, dado que possui um compromisso de garantir a igualdade e a dignidade humana, valores e princípios diretamente relacionados com o direito à saúde, bem como o acesso à justiça. De outro lado, uma vez rompida a inércia inicial, o juiz deve decidir a lide que lhe foi apresentada, ou os tribunais quando se tratar de sua competência originária.

Porquanto,

Banalizaram-se problemas e repostas. Diante da rotina de liminares garantindo a entrega de praticamente todo e qualquer medicamento e providência requerido, qualquer medida oferecida no âmbito do sistema de saúde, ainda que célere e razoável, tende a ser vista como emulação acanhada do verdadeiro direito subjetivo do interessado. Nada menos que a providência máxima será tido como aceitável. Seria como parafrasear o antigo ditado: aos que tiverem a sorte do caminho judicial, tudo; à coletividade, a lei. $\mathrm{O}$ direito à de um oposto ao direito à saúde de muitos (BUCCI, 2017, p. 34).

Conforme se percebe, o exercício do contraditório é cumprido como mera formalidade do procedimento processual, não se considerando a credibilidade das alegações, eis que muitas 
vezes as liminares são concedidas de plano, já garantindo o direito, sem se averiguar as condições daquele que o pleiteia, isto é, é preferível garantir o que se solicita e passar um caso na frente daqueles que estão na fila aguardando a prestação de saúde, ao invés, de analisar de maneira razoável durante o procedimento processual, ponderando todas as argumentações das partes. Ademais, ressalte-se que as partes apenas aceitam receber aquilo que pedem, não havendo a possibilidade de eventual acordo.

Há de se considerar ainda que todos os direitos são onerosos, uma vez que eles pressupõem o financiamento do contribuinte em máquinas de supervisão eficientes e eficazes para monitorar e cumprir a lei.Da mesma forma que um Tribunal depende de recursos para assegurar sua funcionalidade, de modo que,por ser necessária vigilância judicial dos executores dos direitos, gasta-se o mesmo, no mínimo, como se se estivesse contratando, treinando, fornecendo e pagando por guardiões judiciais, que, em retorno, estivessem monitorando os direitos básicos do ser humano (HOLMES; SUSTEIN, 1999, p. 44-45).

É possível notar que, apesar de se valerem de um excesso de interpretação no uso de sua autonomia interpretativa e para solucionar as demandas que interfiram em atribuições dos outros poderes, os magistrados não vem conseguindo solucionar as demandas individuais e coletivas no tocante a sua eficácia e efetividade, pois, na maioria das vezes, nos casos de saúde, as soluções envolvemgastos orçamentários vultosos(para um caso concreto) e tempo exíguo de cumprimento, em consequência, culminam em multas, havendo ainda as demandas não judicializadas e que dependem do cumprimento pelo poder público (ou seja, a organização normal de execução da prestação de saúde daquele dia).

Dessa forma,

assume caráter emergencial uma crescente conscientização por parte dos órgãos do Poder Judiciário, que não apenas podem, como devem zelar pela efetivação dos direitos fundamentais sociais, mas, ao fazê-lo haverão de obrar com a máxima cautela e responsabilidade, seja ao concederem, ou não, um direito subjetivo a determinada prestação social, seja quando declararem a inconstitucionalidade de alguma medida restritiva ou retrocessiva de algum direito social (SARLET, 2018, p. 371).

Consequentemente, a dificuldade de equilibrar os anseios e necessidades sociais com os gastos orçamentários e agendas de atendimento dos serviços públicos de saúde (filas em âmbito administrativo), exige do Poder Judiciário parcimônia, ponderação e muito cuidado, o que poderia ser melhor realizado a partir de um apoio técnico que oferecesse substrato especializado e imparcial a sua decisão.

Importante ressaltar que a judicialização da saúde conduz a ideia de que o autor tem direitos irrestritos, o que não é verdade: 


\begin{abstract}
A jurisprudência do "direito a tudo" tem impacto negativo importante na sustentabilidadedo sistema público de saúde. Isso porque em nenhum país do mundo há recursos suficientes para se oferecer a toda a população todos os tratamentos que conseguem passar pelo crivo regulatório explicado anteriormente. Existem atualmente milhares de medicamentos aprovados na Anvisa e em agências regulatórias pelo mundo afora, vários de empresas diferentes mas para a mesma patologia, com frequência com enorme variação de preço. Todo sistema de saúde precisa fazer escolhas sobre quais medicamentos e tratamentos vai ou não ofertar dentro das inúmeras possibilidades com seu orçamento necessariamente limitado. Esse processo, chamado de incorporação, envolve análise da chamada custoefetividade e do impacto orçamentário dos tratamentos disponíveis. A incumbência dessa tarefa no Brasil é do Ministério da Saúde, com o auxílio da Comissão Nacional de Incorporação de Tecnologias no SUS (Conitec). Há também a participação do Poder Legislativo, que é quem aprova o orçamento da saúde e estabelece os limites financeiros dentro dos quais essas escolhas devem ser necessariamente feitas (FERRAZ, 2019, p. 13).
\end{abstract}

Com efeito, a análise de medicamentos, tratamentos e serviços de saúde passa por avaliações antes de serem disponibilizadas e padronizadas, de sorte que não são todas as solicitações judiciais que devem ser concedidas, haja vista seu impacto não só orçamentário, como também científico, e os reflexos que (e se) eles podem ocasionar na saúde do paciente.

Portanto, o ativismo judicial e a judicialização da saúde oneram os gastos públicos sem se apresentar como uma solução justa, eficaz e efetiva as demandas judiciais de saúde, muito embora, as decisões judiciais pudessem ser mais justas, caso houvesse apoio técnico aos juízes, os quais, inclusive, precisam conhecer e adequar suas decisões à realidade nacional do Sistema Único de Saúde e as necessidades dos requerentes.

\title{
3 A justiça como equidade: a plataforma e-nat jus - uma alternativa
}

Em face do contexto fático-jurídico marcado pela judicialização da saúde, Rawls (1997, p. 7-8) considera como objeto primário da justiça a estrutura básica da sociedade, ou seja, o modo como as instituições sociais mais importantes distribuem os direitos e deveres fundamentais e estabelecem a distribuição das vantagens decorrentes da cooperação social, sendo que as instituições mais importantes se relacionam a constituição política e os principais acordos econômicos e sociais.

A instituição consiste em "um sistema público de regras que define cargos e posições com seus direitos e deveres, poderes e imunidades, etc" (RAWLS, 1997, p. 58). Assim, para se atingir a justiça, é preciso haver um sistema institucional bem sedimentado, no sentido de união social, cooperação e normas sólidas, motivo pelo qual diante do enfrentamento de conflitos gerados pela vida social sua solução advenha da prática social bem consolidada em instituições tal qual a Constituição, os princípios e principais regras vigentes. 
No âmbito do Poder Judiciário, o magistrado também tem deveres perante a lei e à Constituição, de forma que suas decisões devem buscar solucionar os casos da melhor maneira também sob o aspecto de justiça social, isto é, como nas prestações de saúde são muitas as demandas e as políticas públicas, seria interessante priorizar a prestação que não fosse apenas custeada pelo Poder Público, como também por ele fornecida, de outro lado, também incumbe ao Poder Executivo o aprimoramento e constante atualização das políticas públicas prestacionais.

Então, "O dever natural da justiça é a base primeira dos nossos vínculos políticos com um regime constitucional" (RAWLS, 1997, p. 417). Por outro lado, a injustiça se manifesta quando se têm desigualdades que não beneficiam a todos (RAWLS, 1997, p. 62). Logo, ideia é que a justiça seja o norte e o cerne do ordenamento constitucional, os direitos sejam iguais e distribuídos entre todos da mesma forma, e, caso existam desigualdades, elas devem razoavelmente beneficiar a todos, se não se opera a injustiça.

De tal maneira, um direito positivado constitucionalmente, assegurado mediante prestações a serem fornecidas pelo poder público quando, por meio de processos judiciais algumas pessoas acabam obtendo vantagens na sua garantia, o que implica em prestações de valores exorbitantes, passando na frente daqueles que estão esperando o procedimento, sem a tutela jurisdicional, e, nos casos de pessoas que sequer sabem que podem solicitar o amparo judicial para obter prestações de saúde, efetuam-se desproporções desiguais que indicam injustiças.

Ocorre que, a união de fatores como a abertura interpretativa, a judicialização das escolhas políticas e a afirmação de um amplo espectro de controle por parte do Judiciário resultam na produção de uma nova seletividade que não depende de um critério legislativo formal estabelecido no sistema jurídico, e sim de quando o juiz perceber que não está mais limitado a uma racionalidade formal, ignorando a pessoa que está na posição central. Passa-se a evocar uma racionalidade material, fruto de um processo interno de leitura e interpretação de cada juiz, apto a superar todos os argumentos opostos ao que se acredita ser a concretização dos direitos fundamentais (VALLE, 2011, p. 202).

Não obstante a Constituição atuar como sustentáculo da justiça, dos direitos fundamentais e do próprio direito em âmbito interno, a interpretação dos casos sejam eles fáceis, difíceis ou trágicos deve seguir o raciocínio constitucional, no entanto sem margem para aberturas interpretativas e ampliações de sentido, caso contrário estar-se-á selecionando o que julgar, a forma como julgar e a favor de quem se julgar, razão pela qual ainda que a Constituição sejaa norma suprema, existem outras leis estabelecendo limites que devem ser observadas, bem 
como as disposições constitucionais relativas à separação, independência e harmonia entre os poderes, os objetivos e fundamentos do Estado Brasileiro.

Ressalve-se que as concessões judiciais com base no direito a tudo interferem na:

equidade do sistema, promovendo uma separação entre aqueles que têm efetivamente acesso a tudo, via Justiça, e os que têm acesso apenas aos medicamentos e tratamentos ofertados com os recursos limitados do sistema público, cada vez mais afetados pelos crescentes gastos com a judicialização (FERRAZ, 2019, p. 14).

Assim, para que se possa tornar o processo ou o íter processual mais justo e equânime é preciso apoio técnico ao judiciário, não no sentido de vinculá-lo, mas com o escopo de aclarar questões médicas e sanitárias das quais o juiz não tem formação.

Nesse sentido, o Conselho Nancional de Justiça (CNJ), após algumas deliberações que não atingiram o resultado esperado, instituiu a Plataforma eletrônica denominada eNAT-Jus, em 2019, pelo Provimento 84/2019¹, o CNJ em parceria com o Hospital Israelita Albet Einstein

${ }^{1}$ PROVIMENTO No 84, DE 14 DE AGOSTO DE 2019. Dispõe sobre o uso e o funcionamento do Sistema Nacional de Pareceres e Notas Técnicas (e-NatJus). [...] RESOLVE: Art. $1^{\circ}$ Os Magistrados Estaduais e os Magistrados Federais com competência para processar e julgar ações que tenham por objeto o direito à saúde, ainda que durante o plantão judicial, quando levados a decidirem sobre a concessão de determinado medicamento, procedimento ou produto, poderão solicitar apoio técnico ao Núcleo de Apoio Técnico do Judiciário (NAT-JUS) do seu Estado ou ao NAT-JUS NACIONAL.

$1^{\circ} \mathrm{O}$ apoio técnico previsto no caput, quando solicitado, deverá ser materializado por meio do Sistema Nacional de Pareceres e Notas Técnicas (e-NatJus), hospedado no sítio do Conselho Nacional de Justiça, podendo ser acessado através do link: www.cnj.jus.br/e-natjus.

$2^{\circ}$ Nas hipóteses em que o Tribunal local já dispuser de um sistema próprio de apoio técnico, o Magistrado poderá solicitar por meio do sistema do seu Tribunal, sendo que emitido o parecer no caso concreto, o Núcleo de Apoio Técnico ao Judiciário (NAT-JUS) deverá alimentar a base de dados do Sistema Nacional de Pareceres e Notas Técnicas (e-NatJus), com suas respectivas notas técnicas.

$3^{\circ} \mathrm{O}$ Tribunal que já dispõe de sistema próprio de solicitação de apoio técnico, por intermédio do seu Núcleo de Apoio Técnico ao Judiciário (NAT-JUS), quando tiver a necessidade de tutoria para elaboração de suas notas técnicas, junto aos NATS selecionados, conforme previsto no Termo de Cooperação $n^{\circ}$ 021/2016, celebrado entre o Conselho Nacional de Justiça e o Ministério da Saúde, deverá solicitar através do Sistema Nacional de Pareceres e Notas Técnicas (e-NatJus).

$4^{\circ}$ Nas demandas com pedido de tutela antecipada sob a alegação de urgência, conforme previsto no Termo de Cooperação Técnica n ${ }^{\circ}$ 051/2018, celebrado entre o Conselho Nacional de Justiça e o Ministério da Saúde, o Magistrado, quando tiver a necessidade de apoio técnico do NAT-JUS NACIONAL, ainda que o Tribunal disponha de sistema próprio, e neste caso, determinará por decisão, a solicitação de nota técnica diretamente por meio do Sistema Nacional de Pareceres e Notas Técnicas (e-NatJus).

Art. $2^{\circ}$ Os Tribunais que já dispõe de sistema próprio, além de poder utilizar o sistema e-NatJus, nas formas anteriormente previstas, poderão utilizá-lo através dos mecanismos de integração de sistemas de processo eletrônico.

Art. $3^{\circ} \mathrm{O}$ acesso ao sistema e-NatJus será concedido aos servidores indicados pelos:

I - Magistrados com competência para processar e julgar ações que tenham por objeto o direito à saúde, cuja finalidade é dar início ao pedido de apoio técnico ao NAT-JUS do Estado ou NAT-JUS NACIONAL;

II - Núcleos de Apoio Técnico ao Judiciário (NAT-JUS), cuja finalidade é atender à solicitação de apoio técnico requerida pelo Magistrados.

Parágrafo único. Compete às Corregedorias dos Tribunais de Justiça e dos Tribunais Regionais Federais, quando solicitadas, conceder o acesso ao sistema e-NatJus aos servidores mencionados no caput, por meio do Sistema de Controle de Acesso corporativo do CNJ.

Art. $3^{\circ} \mathrm{O}$ Conselho Nacional de Justiça disponibilizará manual de utilização do Sistema Nacional de Pareceres e Notas Técnicas (e-NatJus), com o objetivo de orientar a sua utilização e sanar eventuais dúvidas dos usuários.

Art. $4{ }^{\circ}$ Este Provimento entrará em vigor na data de sua publicação (BRASIL, online). 
e o Ministério da Saúde implantaram a plataforma NAT-JUS Nacional, cujo acesso é em meio eletrônico, inclusive para pesquisa, a partir da sua página na internet. Destarte, o NAT-JUS começou como uma iniciativa estadual de implantação, na qual o estado do Rio de Janeiro foi o pioneiro, e, em 2019, houve a expansão do núcleo a nível nacional, pelo CNJ. A ideia central é fornecer auxílio e segurança ao magistrado nos casos que envolvam direito à saúde.

Além disso, o e-NatJus conta também com o apoio do Hospital Sírio Libanês, o qual capacita os integrantes dos núcleos de cada estado na elaboração das notas técnicas e no encaminhamento de solicitações de pareceres técnicos científicos a serem realizados pelos Comitês Estaduais de Saúde do Judiciário, segundo a Associação de Medicina Paulista (BRASIL, online).

As notas técnicas contêm informações do paciente como idade, sexo e cidade, dados do processo, abrangendo inclusive Juizados Especiais Cíveis, da Fazenda Pública e Federais. Um campo sobre o diagnóstico, em que além dele, há a CID e os meio(s) confirmatório(s) do diagnóstico já realizado(s). Ainda, existem os campos acerca daquilo que se pede, denominados de descrição da tecnologia, no qual existem variados subitens como: outras tecnologias disponíveis, custo da tecnologia, se o produto está disponível no SUS, evidências sobre a eficácia e segurança da tecnologia, benefícios, efeitos ou resultados esperados com a tecnologia, recomendação do CONITEC e a conclusão. Ademais, é preciso destacar que nas notas técnicas constam as referências bibliográficas que auxiliaram os profissionais a realizarem-nas.

Dessa maneira, as notas técnicas vêm adquirindo adesão por parte dos tribunais, seja a partir de sua implementação gradual em cada estado, ou mediante a utilização do sistema eNatJus Nacional, como se pode verificar abaixo:

Agravo de instrumento. Direito à saúde. Fornecimento de medicamento. Judicialização da saúde. 1. O deferimento de tratamentos de saúde antecipadamente, sem a produção de provas além das prescrições do médico assistenteencontra óbiceno entendimento desta Corte, contido no enunciado da Súmula 101. 2. Em que pese a prescrição do médico assistente indique a medicação postulada como alternativa de tratamento, existe parecer de órgão técnico (Nota Técnica nº 42/2014 - NATs/UFMG) referindo não haver vantagem terapêutica deste medicamento sobre aqueles disponíveis junto ao SUS, bem assim informando que o mesmo produz mais efeitos adversos. 3. É a produção de provas, seja aquela produzida em perícia, seja a obtida mediante consulta às avaliações da CONITEC ou dos Núcleos de Avaliação de Tecnologias em Saúde, que pode atestar a correção da prescrição do médico assistente. (TRF4 - Acórdão Ag - Agravo de Instrumento 5016219-24.2018.4.04.0000, Relator(a): Des. Marga Inge Barth Tessler, data de julgamento: 26/06/2018, data de publicação: 26/06/2018, $3^{\text {a }}$ Turma), (BRASIL, online).

Ementa: administrativo. Direito à saúde. Perícia médica. Desnecessidade. Imprescindibilidade do fármaco prescrito. Ocorrência. 1. Sempre que possível, a perícia médica poderá ser substituída por Nota Técnica elaborada pelo Núcleo de Apoio respectivo - no caso, NAT-Jus/SC. 2. Demonstrado, através de Nota Técnica, tanto a anterior utilização de outros fármacos fornecidos pelo SUS quanto a 
necessidade do medicamento postulado, a manutenção da decisão impugnada é a medida adequada. (TRF4, AG 5027042-23.2019.4.04.0000, TURMA REGIONAL SUPLEMENTAR DE SC, Relator PAULO AFONSO BRUM VAZ, juntado aos autos em 17/10/2019), (BRASIL, online).

Portanto, as notas técnicas oferecem a segurança, a celeridade e a confiabilidade ao Judiciário na tomada de decisões, podendo ser um instrumento cada vez mais utilizado e que, possivelmente culminará em decisões mais condizentes à realidade e as necessidades, e, via reflexa, mais equitativas.

Por conseguinte, verifica-se que a justiça como equidade se relaciona a assegurar o princípio da isonomia nas prestações de saúde, tanto quanto aos serviçosprestados quantitativa e qualitativamente pelo poder público, como no tocante à judicialização da saúde pelo apoio técnico fornecido ao magistrado a partir da plataforma e-NatJus, de modo que as notas técnicas não vinculam o juiz, apenas funcionam como orientação e substrato as decisões, posto que os processos não podem ser vistos como forma de se resolver o serviço ou assegurar prestações que comprometam o acesso a prestações de saúde de outras pessoas e também o orçamento público.

\section{Considerações finais}

O direito à saúde possui estrita ligação com a manutenção da vida e a dignidade humana, uma vez que,assegurada uma boa condição de vida é possível manter e prezar por uma boa saúde. No entanto, a sociedade atual é marcada por excessos, excesso de consumo, de poluição, de desigualdade. Ainda, o Brasil não atingiu um ambiente no qual seja possível assegurar a boa saúde, porque existem lugares nos quais não há saneamento básico, a vacinação vem sendo popularmente rejeitada, há a mutação e do surgimento de novas patologias (epidemias e pandemias), dentre outras razões. Então, os ricos à saúde são iminentes e estão por todos os lados.

A saúde como direito está prevista expressamente na Constituição Brasileira de 1988,sendo atribuída aopoder público, no que tange a sua proteção, recuperação e promoção, mediante políticas públicas. De tal maneira, sua garantia se tornou ineficaz e ineficiente, vez que a quantidade de demanda não é suprida pela qualidade do serviço, se existente. Por essa razão, invoca-se o Poder Judiciário em busca de uma solução que seja a prestação de um serviço de saúde, como uma interpretação da disposição constitucional do direito à saúde e da garantia do acesso à justiça. 
Ocorre que grande parte das decisões judiciais interfere no orçamento público, no fornecimento do serviço, na gestão das políticas públicas de saúde, algumas extrapolam na interpretação do caso concreto, nos limites constitucionais e solucionam as lides de maneira inexequiível. Logo, instaura-se um caos na saúde pública, pois os serviços públicos prestados não funcionam, os processos aumentam potencialmente (evidencia-se uma clara desigualdade entre aquele que busca o serviço pelo processo judicial e o que espera o serviçoadministrativamente), tal qual os gastos, que são limitados.

Portanto,disto se infere que a judicialização da saúde e o ativismo judicial dela decorrente não contribuem para melhorar ou minorar os problemas na saúde pública, por outro lado, acabam por estabelecer mais desigualdades, problemas de gestão e gastos públicos. A alternativa, além da melhoria do serviço público em saúde, que deve ser mais disseminado, qualitativa e quantitativamente, atentando-se também aos desiguais no limite de suas desigualdades, consiste, no âmbito processual, em respostas judiciais mais racionais, justas e equitativas, como a utilização da Plataforma e-NatJus, pela qual é fornecido apoio técnico especializado ao magistrado, mediante notas técnicas, as quais elucidam o que se pleiteia, de acordo com a realidade de fornecimento nacional e qualificando os pedidos autorais como necessidades urgentes ou não.

Assim, apesar da Plataforma e-NatJus não resolvertodos os problemas advindos da judicialização da saúde, bem como não eximir a responsabilidade dos poderes Legislativo e Executivo na elaboração e materialização de políticas públicas, ela permitirá, em sendo incorporada cada vez mais nos Juízos brasileiros, que haja uma diminuição nos gastos públicos judiciais com saúde, possibilitando investimentos que beneficiem a coletividade e sentenças (de casos individuais) mais justas e equitativas, uma vez que o direito à saúde é fundamental e subjetivo, porém não absoluto, coletivo e universal.

\section{Referências}

BARCELLOS, Ana Paula de et al. Direito à saúde e prioridades: introdução a um debate inevitável. Rev. direito GV, São Paulo, v. 13, n. 2, p. 457-483, ago. 2017. Disponível em http://www.scielo.br/scielo.php?script=sci_arttext\&pid=S1808-

24322017000200457\&lng=pt\&nrm=iso. Acesso em: 20 abr. 2019.

BARROSO, Luís Roberto. Constituição, democracia e supremacia judicial: direito e política no Brasil contemporâneo. RFD- Revista da Faculdade de Direito- UERJ, v. 2, n. 21, jan./jun. 2012.

BRASIL. Associação Paulista de Medicina. Notícias em destaque. Judicialização: juízes terão médicos de plantão para auxilia-los nas decisões. Disponível em: 
http://www.associacaopaulistamedicina.org.br/noticia/judicializacao-juizes-terao-medicos-deplantao-para-auxilia-los-nas-decisoes. Acesso em: 16 out. 2019.

BRASIL. Constituição (1988). Constituição da República Federativa do

Brasil: promulgada em 5 de outubro de b1988. Disponível em:

http://www.planalto.gov.br/ccivil_03/constituicao/constituicaocompilado.htm. Acesso em: 04 fev. 2019.

BRASIL. Provimento no 84 de 14/08/2019 do CNJ. Disponível em: https://atos.cnj.jus.br/atos/detalhar/2987. Acesso em: 16 out. 2019.

BRASIL. Tribunal Regional Federal da $4^{\text {a }}$ Região. Agravo de Instrumento 501621924.2018.4.04.0000. Disponível em: https://oabjuris.legalabs.com.br/process/ace0a53e6a3c3c88b639de3e4585d01bff71d00ce48d4 b9c73f27dde956b3c72. Acesso em: 22 out. 2019.

BRASIL. Tribunal Regional Federal da $4^{\text {a }}$ Região. Agravo de Instrumento 502704223.2019.4.04.0000. Disponível em:

https://jurisprudencia.trf4.jus.br/pesquisa/citacao.php?doc=TRF420034782. Acesso em: 22 out. 2019.

BUCCI, Maria Paula Dallari. Contribuição para a redução da judicialização da saúde: uma estratégia jurídico-institucional baseada na abordagem de Direito e Políticas Públicas. In: BUCCI, Maria Paula Dallari; DUARTE, Clarice Seixas (Coord.). Judicialização da saúde: a visão do poder executivo. São Paulo: Saraiva, 2017. p. 31-88.

CITTADINO, Gisele. Poder Judiciário, ativismo judicial e democracia. ALCEU, v.5, n.9, p. 105 a 113, jul./dez 2004.

CUNHA, Alexandre Luna da. A integralidade do direito à saúde na visão do Supremo Tribunal Federal. Revista De Direito Sanitário, v. 20, n. 1, p. 167-184, 18 nov. 2019. Disponível em: http://www.revistas.usp.br/rdisan/article/view/164214. Acesso em: 27 mar. 2020.

DALLARI, Sueli Gandolfi; NUNES JÚNIOR, Vidal Serrano. Direito Sanitário. São Paulo: Editora Verbatim, 2010.

DE CARVALHO, Ernani Rodrigues. Em busca da judicialização da política no Brasil: apontamentos para uma nova abordagem. Revista de sociologia e política, Curitiba, n. 23, p. 115-126, nov. 2004. Disponível em: https://revistas.ufpr.br/rsp/article/download/3699/2949. Acesso em: 10 jan. 2019.

FERRAZ, Octávio Luiz Motta. Para equacionar a judicialização da saúde no Brasil. Revista Direito GV, [S.1.], v. 15, n. 3, p. e. 1934, nov. 2019. ISSN 2317-6172. Disponível em: http://bibliotecadigital.fgv.br/ojs/index.php/revdireitogv/article/view/80712. Acesso em: 29 mar. 2020.

FEREJOHN, John. Judicializing politics, politicizing law. Law and contemporary problems, v. 65, n. 3, p. 41-68, 2002. Disponível em: www.jstor.org/stable/1192402. Acesso em: 19 out. 2018. 
FERREIRA FILHO, Manoel Gonçalves. A Constituição de 1988 e a judicialização da política. Revista da Faculdade de Direito, v. 12, n. 12, 1996. Disponível em:

https://www.seer.ufrgs.br/revfacdir/article/download/69181/39070. Acesso em: 10 jan. 2019.

FIGUEIREDO, Mariana Filchtiner. Direito fundamental à saúde: parâmetros para sua eficácia e efetividade. Porto Alegre: Livraria do Advogado Editora, 2007.

HÖFFE, Otfried. JUSTIÇA POLÍTICA: Fundamentação de uma filosofia crítica do direito e do Estado. São Paulo: Martins Fontes, 2006.

HOLMES, Stephen; SUSTEIN, Cass R. The cost of rights: why liberty depends on taxes. New York: W. W. Norron\& Company, 1999.

MACHADO, Edinilson Donisete. Ativismo judicial: limites institucionais democráticos e constitucionais. 1. ed. São Paulo: Letras Jurídicas, 2011.

MARQUES, Alineet al. Judicialização da saúde e medicalização: uma análise das orientações do Conselho Nacional de Justiça. Estud. av., São Paulo , v. 33, n. 95, p. 217-234, Jan. 2019 . Disponível em: http://www.scielo.br/scielo.php?script=sci_arttext\&pid=S010340142019000100217\&lng=en\&nrm=iso. Acesso em: 08 abr. 2020.

NUNES JÚNIOR, Vidal Serrano. A Cidadania Social na Constituição de 1988 - Estratégias de Positivação e Exigibilidade Judicial de Direitos Sociais. São Paulo: Editora Verbatim, 2009.

ORGANIZAÇÃO MUNDIAL DA SAÚDE (OMS). Constituição da Organização Mundial da Saúde (OMS/WHO) - 1946. Disponível em:

http://www.direitoshumanos.usp.br/index.php/OMS-Organiza\%C3\%A7\%C3\%A3o-Mundialda-Sa\%C3\%BAde/constituicao-da-organizacao-mundial-da-saude-omswho.html. Acesso em: 04 abr. 2018.

RAWLS, John. Uma teoria de justiça. São Paulo: Martins Fontes, 1997. Tradução de: Almiro Pisetta e Lenita M. R. Esteves.

SARLET, Ingo Wolfgang. A eficácia dos direitos fundamentais: uma teoria geral dos direitos fundamentais na perspectiva constitucional. 13. ed. rev. e atual. Porto Alegre: Livraria do Advogado, 2018.

SEGRE, Marco; CARVALHO, Ferraz Flávio. O conceito de saúde. Revista de Saúde Pública, v. 31, n. 5, p. 538-542, 1997. Disponível em:

https://www.scielosp.org/scielo.php?pid=S0034-

89101997000600016\&script=sci_arttext\&tlng=pt\#. Acesso em: 10 jan. 2019.

SERRANO, Mônica de Almeida Magalhães. O sistema único de saúde e suas diretrizes constitucionais. 2.ed. São Paulo: Editora Verbatim, 2012.

STRECK, Lenio Luiz. Os dilemas do Estado Constitucional: entre a democracia e o presidencialismo de coalizão. LAZARI, Rafael; BERNARDI, Renato. Crise Constitucional: espécies, perspectivas e mecanismos de superação. Rio de Janeiro: Lumen Juris, 2015, p. 318. 
FORTUNATO, Beatriz Casagrande; BOTELHO, Marcos César. Descompasso na saúde pública: o acesso à justiça e a judlicialização versos o direito à saúde na Constituição de 1988

VALLE, Vanice Lírio do. Judicialização das Políticas Públicas no Brasil: até onde nos podem levar as asas de Ícaro. Themis: Revista de direito, v. 11, n. 20, p. 185-210, 2011. 